See Article page 1029.

\section{Commentary: Management outcomes of primary pulmonary vein stenosis: What we know now and what we can expect in the future}

\author{
Haifa Hong, MD, PhD
}

Primary pulmonary vein stenosis (PPVS) may be one of the most challenging cases in the pediatric cardiovascular diseases. Because of its rarity, PPVS is also one of diseases with which most pediatric cardiac cardiologists and surgeons lack experience. Even with its small population, the study by Rosenblum and colleagues ${ }^{1}$ reported in this issue of the Journal represents the largest PPVS series reported to date.

The authors report unsatisfactory results with both primary surgical repair and initial percutaneous intervention. Nonetheless, the study contributes to our understanding of the treatment and management of PPVS. For example, nearly $82 \%$ patients underwent a sutureless technique with no improvement in outcomes, possibly demonstrating the need for modification of existing surgical techniques for PPVS and showing that novel surgical techniques or adjuvant medical therapy merit investigation. Moreover, the percutaneous outcomes of this study in high-risk patients are very disappointing, which indicates that primary surgical repair may be the preferred choice for PPVS. Finally, the authors demonstrate the effectiveness of PPVS severity score in identifying the risks of mortality and reintervention, highlighting the importance of multi-institutional studies in the future for developing a universal PPVS severity score.

One limitation that the authors do not mention is the positional relationship of the pulmonary veins with the atria,

\footnotetext{
From the Cardiothoracic Surgery Department, Shanghai Children's Medical Center, Shanghai Jiaotong University School of Medicine, Shanghai, China.

Disclosures: Author has nothing to disclose with regard to commercial support.

Received for publication Oct 30, 2019; revisions received Oct 30, 2019; accepted for publication Oct 30, 2019; available ahead of print Jan 10, 2020.

Address for reprints: Haifa Hong, MD, PhD, Cardiothoracic Surgery Department, Shanghai Children's Medical Center, Shanghai Jiaotong University School of Medicine, 1678 Dongfang Rd, Shanghai, China (E-mail: hhfsmallboat@gmail. com).

J Thorac Cardiovasc Surg 2020;159:1039

$0022-5223 / \$ 36.00$

Copyright (c) 2019 by The American Association for Thoracic Surgery

https://doi.org/10.1016/j.jtcvs.2019.10.201
}

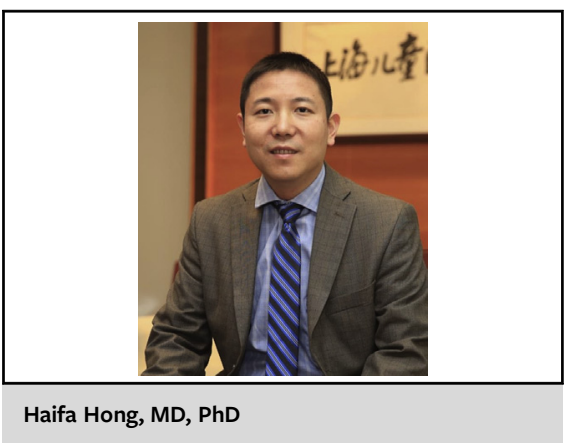

CENTRAL MESSAGE

Primary pulmonary vein stenosis management still has a long way to go.

especially considering the $>90 \%$ of patients in this cohort had an associated congenital heart disease. In our surgical experience, as well as that of other groups, the positional relationship between the pulmonary veins and bilateral atria is variable in total anomalous pulmonary venous connection (TAPVC), and this relationship is important for determining the optimal surgical approach. ${ }^{2,3}$ Some work is being done on using $3 \mathrm{D}$ printing technology to investigate the 3dimensional positional relationship of pulmonary veins and the atria in complicated TAPVC cases before surgery. Because pulmonary veins are very susceptible to rotation and distortion of the anastomosis angle, it is reasonable to suppose that the 3-dimensional positional relationship of the pulmonary veins with the atria in PPVS may be one of main factors in the poor results, especially in cases with diffuse and long-term pulmonary venous stenosis. Thus, more information on the 3-dimensional positional relationship of pulmonary veins and the atria in this cohort of patients, as well as other multi-institutional PPVS patients, may help improve our understanding of this complex disease and determine the optimal surgical approach.

\section{References}

1. Rosenblum JM, Altin HF, Gillespie SE, Bauser-Heaton H, Kanter KA, Sinha R, et al. Management outcomes of primary pulmonary vein stenosis. J Thorac Cardiovasc Surg. 2020;159:1029-36.e1.

2. Peng Y, Ge Y, Zhang H, Liu J, Hong H, Lu Y. Positional relationship between the pulmonary venous confluence-vertical vein and atria in infracar diac total anomalous pulmonary venous connection. Pediatr Cardiol. 2016; 37:372-7.

3. Tekbas G, Gumus H, Onder H, Ekici F, Hamidi C, Tekbas E, et al. Evaluation of pulmonary vein variations and anomalies with 64-slice multidetector computed tomography. Wien Klin Wochenschr. 2012;124:3-10. 